

\section{Júlio Bressane e os jogos de designação}

\author{
Júlio Bressane and the \\ designation games
}

\section{Alexandre Rocha da Silva' Cassio de Borba Luca²}

\section{Resumo}

Júlio Bressane e os jogos de designação analisa as estratégias de representação do filme O Mandarim (1995). Na análise dos jogos de designação que o diretor engendra, podem-se perceber três momentos distintos: uma representação tradicional, que resguarda a identidade dos personagens indicados (Fernando Eiras representa iconicamente Mário Reis, Gilberto Gil representa indicialmente Sinhô, Gal Costa representa simbolicamente Carmen Miranda); uma designação nômade, que passa de um representâmen a outro (Tom Jobim é representado por Edu Lobo e, na mesma cena, por Fernando Eiras); e uma designação múltipla que identifica uma linha contínua conectando estilisticamente Mário Reis, Chico Buarque e Noel Rosa. O audiovisual, assim, aponta para uma postura fabuladora em que a semiose da música tem primazia sobre as identidades atribuídas a seus intérpretes e compositores.

\section{Palavras-chave}

Designação; cinema brasileiro; semiótica.

\section{Abstract}

Júlio Bressane and the designation games analyzes the strategies of representation in the movie The Mandarin (1995). There seem to be three types of designation games built by the director: a traditional representation, which sticks to the identities of the indicated characters (through iconic, indexical and symbolic representation); a nomad designation, which migrates from a representamen to the next; and a multiple or polytonal designation which identifies a continuous line that stylistically connects Mário Reis, Chico Buarque and Noel Rosa. The audiovisual, thus, points toward a fabulation posture in which the semiosis of music has primacy over the identities attributed to its interpreters and composers.

\section{Keywords}

Designation; brazilian cinema; semiotics. 


\section{Introdução}

Júlio Bressane, diretor carioca nascido em 1946, foi um dos principais nomes do Cinema Marginal. Com Rogério Sganzerla, dirigiu no ano de 1970 a produtora Belair, que, em seus três meses de atividade, lançou sete longas de baixo-orçamento ${ }^{3}$ (Bressane, 2005, p.38). É uma constante em sua obra a referência intersemiótica de diferentes expressões da cultura brasileira. Isso vem sendo feito por meio: (a) da temática, como a música de Maria Bethânia no documentário Bethânia Bem de Perto (1966), a literatura de Machado de Assis em Brás Cubas (1985) ou ainda o próprio cinema nacional sendo discutido em Cinema Inocente (1980);

(b) da trilha sonora, como, por exemplo, a canção São coisas nossas, de Noel Rosa, em Barão Olavo (1970), entre outras incontáveis incorporações do patrimônio fonográfico brasileiro do século XX;

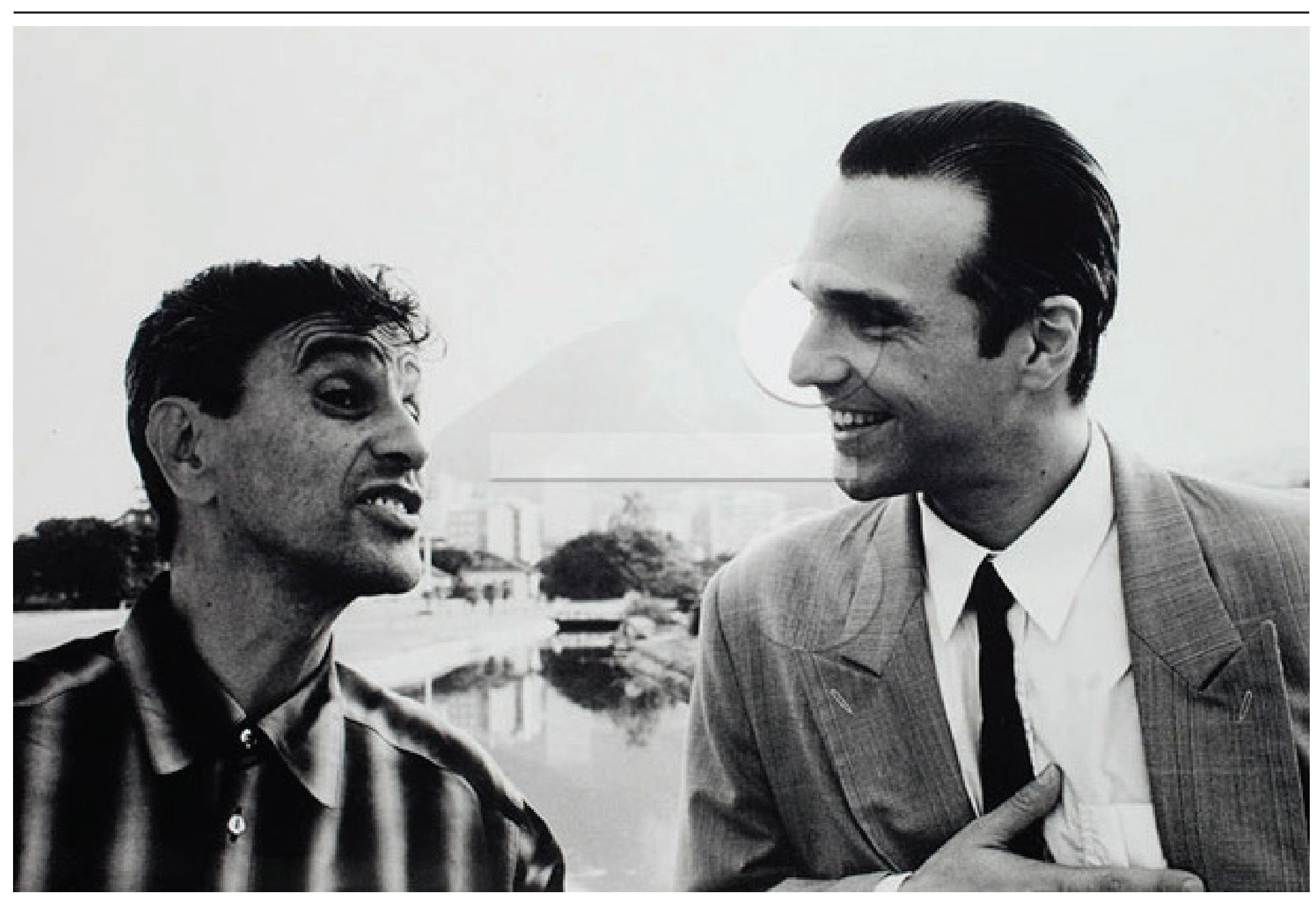

(c) dos diálogos e encontros de personagens culturais históricos, como Oswald de Andrade, que é apresentado a Lamartine Babo por João do Rio em Tabu (1982).

Extrapolando, sem dúvida, este pequeno apanhado, a exploração de signos de brasilidade parece refletir sua concepção de cinema: um "organismo intelectual demasiadamente sensível e que faz fronteira com todas as artes, ciências e a vida" (Bressane, 1996, p.37). E também um organismo "trans-tudo, nômade" (Bressane, 2000, p.23), "onde tudo se traduz, tudo se dobra e se desdobra. Chega à borda e transborda!" (Bressane, 1996, p.42).

Em O Mandarim (1995), Júlio Bressane explora a fronteira do cinema com a música brasileira, retratando o cantor Mário Reis de uma forma não-biográfica, em que o foco muitas vezes escapa à diegese central para explorar os signos que constituíram a vida e a época do protagonista/cantor. Este artigo propõe-se a analisar algumas das semioses engendradas pelo diretor neste movimento.

As sequências analisadas foram selecionadas inicialmente pela propriedade comum de envolver artistas conhecidos da música brasileira (Sinhô, Tom Jobim, Noel Rosa, Carmen Miranda, Villa-Lobos, Gal Costa, Chico Buarque, Gilberto Gil). A riqueza das conexões e especialmente das referências que o filme traz à tona levou à constituição do objeto deste artigo: os modos de representação utilizados pelo diretor e a identificação de sua tese (crítica) a respeito das designações, um dos aspectos fundamentais que estatui a proposição. Analisar o filme, portanto, como proposição significa distinguir, para cada sequência, aspectos relativos a três dimensões da proposição (Deleuze, 1975): quem realiza a manifes-

09 PORTO ALEGRE | v. 19 | n. 32 | 2014 | pp. 08-17 Sessões do Imaginário 
tação, o que é designado, como se articulam plano de expressão e plano de conteúdo.

\section{As dimensões da proposição}

Deleuze dedica um capítulo à proposição, por meio da qual seriam exprimíveis os acontecimentos, na Lógica do Sentido, de 1969. O autor francês apresenta, ali, três relações distintas da proposição com as quais "muitos autores concordam" (Deleuze, 1975, p.13), para depois acrescentar uma dimensão suplementar: a do sentido.

A primeira dimensão é chamada designação ou indicação: "é a relação da proposição a um estado de coisas exteriores" (Deleuze, 1975, p.13). Opera pela associação das palavras com o objeto e o estado de coisas designado, os quais elas devem representar. Pode ser tida como a função informativa da proposição. Portanto, a indicação tem relação, em termos lógicos, com a verdade e a falsidade, e a proposição é considerada verdadeira quando "é efetivamente preenchida pelo estado de coisas", ou seja, quando está adequada ao estado de coisas representado. À luz da "intuição designadora", dizemos de uma palavra, em relação a um objeto: "é isto" ou "não é isto". Fernando Eiras, em O Mandarim, é Mário Reis; na medida em que representa e indica o cantor.

Outra dimensão da proposição é a significação. Trata-se da relação da palavra com conceitos universais ou gerais. Do ponto de vista da significação, consideramos sempre os elementos da proposição como 'significante' das implicações de conceitos que podem remeter a outras proposições, capazes de servir de premissa à primeira (Deleuze, 1975, p.15). A função da significação, em outras palavras, é a ligação entre o plano de expressão e o plano de conteúdo4.
Encerrando o círculo da proposição (Deleuze, 1975, p. 18), tem-se a dimensão da manifestação. É a relação da proposição com o sujeito que fala e se exprime, correspondente às crenças e desejos desse eu manifestante. Essa dimensão, nota Deleuze, é a que possibilita toda a classe, já mencionada, dos indicadores, pois os indicadores formais (isto, aquilo, aqui, ontem, etc.), da ordem da designação, só funcionam quando em relação com esse "manifestante de base". Trata-se, ainda, do domínio do "pessoal", em que a dicotomia lógica não é mais verdadeiro/falso, e sim veracidade/engano. Esse deslocamento de valores lógicos, que já se encontra na análise do pedaço de cera em Descartes (Deleuze, 1975, p. 15), parece corresponder, no cinema, à passagem de uma forma de veracidade à potência do falso, como se verá adiante.

A manifestação no cinema expressa relações complexas e de diferentes ordens, por ser uma obra coletiva: seu correspondente envolve diferentes 'atores sociais' - a indústria que produz e financia o projeto, o diretor/autor da obra, a equipe que decide os rumos da trama. No caso do cinema de autor, como o é o de Julio Bressane, a ideia da manifestação está fortemente associada ao projeto do diretor, embora, rigorosamente, não possa ser reduzida a ele.

Às três dimensões, Deleuze acrescenta uma quarta: 0 sentido. Este, para Deleuze, é o expresso da proposição, e não existe fora dela. "O sentido é o exprimível, o que se diz das coisas e não a essência ou a coisa em si" (Silva et al., 2012, p. 12). Por isso a pergunta, em Deleuze, não pode ser 'qual o sentido de um acontecimento?', já que o sentido é o próprio acontecimento: a relação que resulta da mistura entre corpos.

Nos filmes de Bressane, pensados à luz desta teoria da proposição, a dimensão da designação se destaca na medida em que os atores eventualmente são personalidades notórias de nossa cultura. Inseridos numa obra em que transitam outras tantas figuras históricas designadas, aparece a necessidade de se indagar: Chico Buarque designa Noel ou manifesta a si mesmo? E Edu Lobo, que é chamado de Tom Jobim (supostamente o designando), mas canta uma melodia própria? Nestes momentos, manifestação e designação entram num jogo que não parece ter uma solução simples, se pautando por uma série de possibilidades de interpretação, numa combinatória do acontecimento engendrada pelo diretor. Estes jogos, que desconstroem o conceito tradicional de designação, serão discutidos a seguir.

\section{Os jogos de designação}

A partir das dimensões da proposição acima apresentadas, as sequências de $O$ Mandarim passaram a ser mapeadas com o objetivo de se identificarem as estratégias designativas adotadas pelo diretor, que culminam com a expressão de sua tese: a de que há uma certa indecidibilidade entre designado e designante, uma vez que ambos são efeitos de um mesmo processo semiótico desconstrutivo que consiste em afirmar a anterioridade da cultura, do cinema e da música em relações a seus autores e aos objetos que designam. Como se Bressane dissesse, à luz de Villa-Lobos: estamos na música (e por extensão no cinema); é ela que nos faz, e não o contrário.

Assim, este artigo pretende evidenciar os modos como Bressane foi desconstruindo as designações em O Mandarim até chegar a uma espécie de indecidibilidade cuja expressividade não pode ser compreendida senão através do jogo. Nesse jogo, por vezes, a indicação do designado é dada por marcas indiciais fortes, 
como na cena em que Gal Costa é chamada de "pequena notável" ao interpretar Carmem Miranda. Em outros momentos, há mais de um referente possível, o que começa a embaralhar o jogo: Chico Buarque, chamado no filme de Noel Rosa (supostamente o designando), canta tanto canções suas quanto de Noel; Semelhantemente, Caetano afirma ter sido parceiro de Sinhô, mas este faleceu em 1930, o que dá ensejo à interpretação da fala como referência a Gilberto Gil, seu companheiro de tropicália que interpreta Sinhô neste filme.

Por fim, há momentos em que a designação sofre um abalo fatal, como, por exemplo, quando o diretor aproxima Sinhô e Pixinguinha a partir da sobreposição de suas canções, criando uma nova música que não se deixa atribuir a um compositor ou a outro. Diante disso, verificamos que Bressane tende a realizar, em termos gerais, duas espécies de designação em seu cinema.

À primeira damos o nome de designação diegética, que ocorre quando a própria cena dá indicação de que uma tal figura designa um certo personagem. Eiras é, desde os momentos iniciais do filme, chamado de "meu caro Mário!": signo diegético que implica uma representação, por parte do ator, do cantor da primeira metade do século XX. Em suma, diegéticas são as designações claramente ligadas à sucessão de fatos da narrativa: as designações que se estabelecem "conforme a ficção que o filme apresenta", pois diegético é "tudo o que essa ficção implicaria se fosse supostamente verdadeira" (Aumont e Marie, 2006, p. 77). Esse tipo de designação se conforma a um cinema que mantém sua forma de verdade e se estatui a partir de identidades fixas ou, pelo menos, estáveis em sua referencialização.

Ao segundo tipo de designação, chamamos de extradiegético, e ocorre quando há alusão a conceitos que não correspondem necessariamente às designa- ções identitárias (ator-representado) que se desenvolvem no filme. Isto acontece quando Fernando Eiras, designando diegeticamente Mário Reis, se apropria dos trejeitos vocais de Tom Jobim e passa a designar este último extradiegeticamente. Outro exemplo: em várias sequências é relevante a detecção de um dado compositor como referente, cujo nome não é mencionado, mas que não deixa de ser designado por sua música ou por outras menções indiretas.

$\mathrm{Se}$, genericamente, podem-se identificar designações marcadamente diegéticas e designações que necessitam de referências extradiegéticas, para os propósitos deste artigo ainda é necessário desenvolver mais uma tipologia das designações para que nos aproximemos das estratégias adotadas por Bressane. Apresentadas a seguir, tratam-se das designações (1) identitárias - de natureza icônica (Mário/Eiras), indicial (Sinhô/Gil) e simbólica (Carmen/Gal), (2) nômades (Edu-Tom-Mário) e (3) múltiplas ou politonais (Chico/Noel/Mário).

\section{Designações identitárias}

O primeiro tipo de designação verificado é aquele em que ator e personagem entretêm relações estáveis, nas quais as identidades são resguardadas. Os casos seguintes são pensados com o auxílio da segunda tricotomia de signos de Peirce (2012, p. 52), que diz respeito às relações do signo com seu objeto.

Fernando Eiras interpreta o protagonista Mário Reis, que, nas figuras 1 e 2, canta Jura, de Sinhô. No registro sonoro, é reproduzida a gravação de Mário de 1928, ouvida na íntegra. No registro visual, Eiras faz uma dublagem mimeticamente detalhista de Mário Reis. Sua expressão facial assemelha-se à de Mário Reis, especialmente nos movimentos das sobrancelhas, e também seus gestos, inclusive o dos dedos levantados, típico da marchinha. Sua sombra forma uma silhueta perfeita do personagem designado.
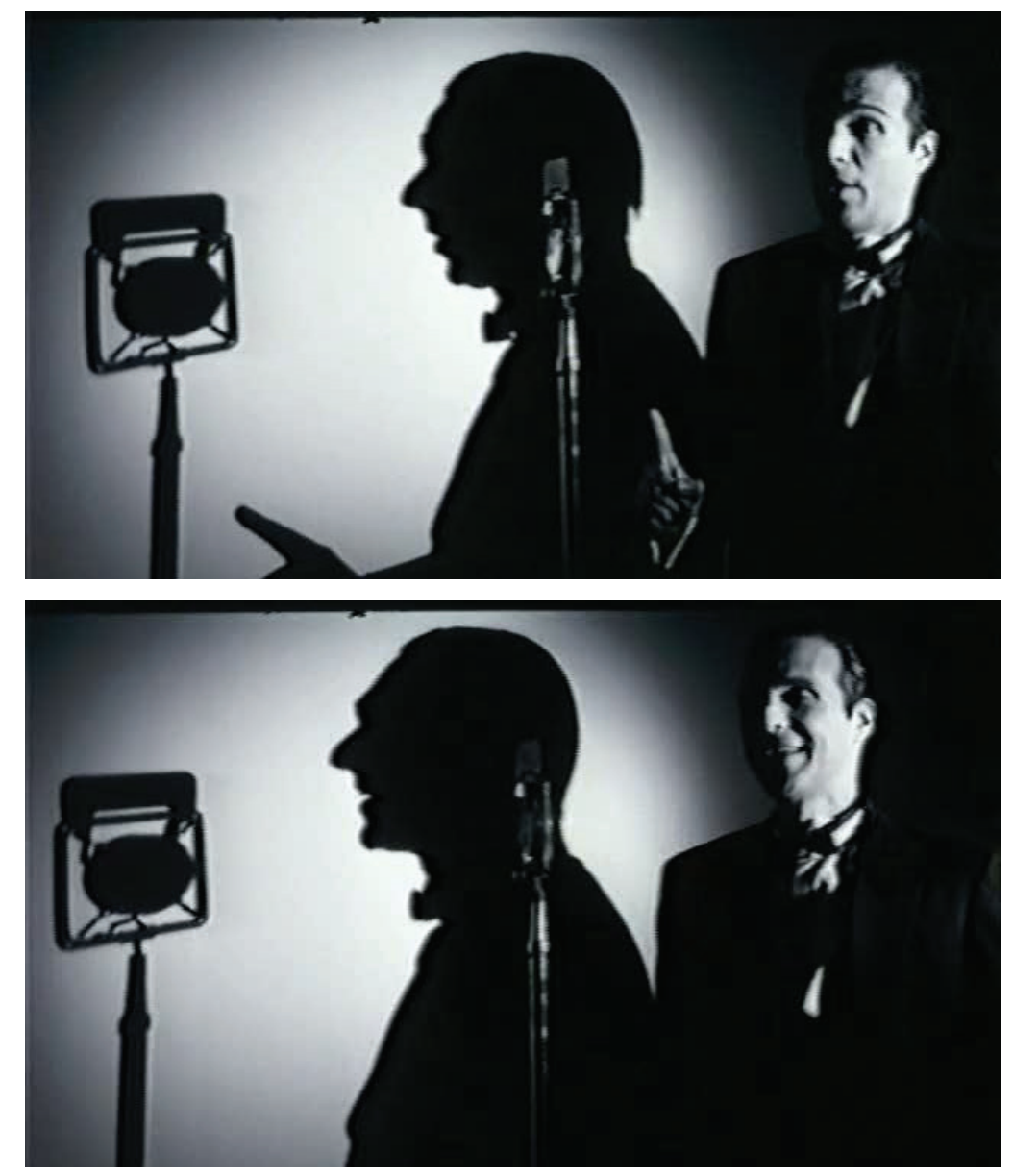

Figuras 1 e 2: A perspectiva icônica - Mário Reis/Fernando Eiras

Percebe-se, aqui, do ponto de vista da manifestação, que o diretor escolhe um tipo de representação tradicional ao decidir que Fernando Eiras representaria por convenção Mário Reis, o designado. A significação é construída para dar veracidade à primazia da designação, posto que a expressão é uma coleção de signos e trejeitos que remetem de imediato ao conceito Mário Reis. Fernando Eiras é, no Mandarim, o representante do que acima

11 PORTO ALEGRE | v. $19 \mid$ n. 32 | 2014 | pp. 08-17 Sessões do Imaginário 
chamamos de designação diegética em sua forma mais evidente. $O$ estilo impresso no plano de expressão é a ferramenta do ator para seguir remetendo à designação realizada na diegese ("caro Mário"), para continuar representando a identidade de seu personagem.

Em termos semióticos, trata-se de uma representação predominantemente icônica ${ }^{5}$, em que os caracteres apresentados são relacionados por semelhança com os caracteres do objeto. Em Peirce, esta categoria de representação envolve um "objeto de experiência na medida em que alguma de suas qualidades faça-o determinar a ideia de um [outro] objeto" (Peirce, 2012, p.52). A atuação de Fernando é mimética neste sentido: 0 ator faz a imitação das particularidades expressivas de Mário Reis, presta atenção aos detalhes qualitativos do referente, e tanto melhor executa sua função quanto melhor faz determinar num interpretante a ideia de seu referente.

Sinhô, compositor dos anos 20, representado por Gilberto Gil em O Mandarim, dialoga (Figuras 4 e 5) com Mário Reis, que foi seu aluno de violão e intérprete. No registro verbal, podem-se notar estes papeis: dá conselhos a Mário', elege-o como seu "intérprete ideal".

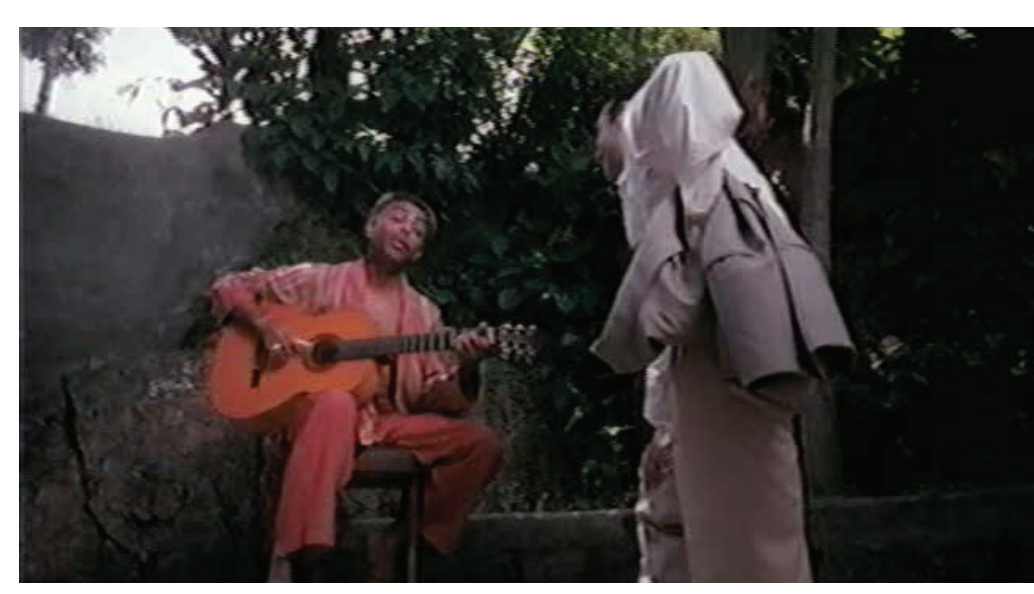

Relativamente, de forma mais específica, à designação, vemos nestas sequências uma concomitância entre designação diegética e designação extradiegética que aparece pela primeira vez. A primeira se configura quando Mário-Eiras chama Sinhô pelo nome (e também, na mesma frase, pela alcunha: "rei do samba!"). A designação extradiegética ocorre quando o estilo de Gil se impõe nas interpretações das canções de Sinhô. Este é seu artifício para representar, extradiegeticamente, a si mesmo: como diz o próprio Sinhô no filme, essa é uma questão de "voz" e "silabar".

Este jogo faz circularem Gil como manifestante e designado extradiegeticamente e Sinhô como personagem designado diegética e extradiegeticamente. Nesse ponto, ainda que dentro de uma lógica de representação tradicional, já se pode vislumbrar a complexidade das relações promovidas pelo diretor entre seu filme e os personagens da música brasileira. A designação vai se fazendo menos confiável como indicação individual e indiciária, se desenvolvendo rumo a um signo múltiplo, obra aberta, que realiza diversas conexões de uma só vez.

Na cena anterior, a representação de Mário Reis ainda preservava natureza marcadamente icônica - um sinsigno icônico, um existente que comporta as qualidades que remetem a seu referente; nesta, como vimos, Gilberto Gil também é um sinsigno, mas se insinua sobre seu designado, adiciona qualidades ao objeto. Em alguma medida, a atuação de Gil ainda é presa indicialmente a Sinhô; sempre se mantém uma determinação de Sinhô na participação de Gil, na exata medida em que este remete àquele. Assim sendo, a designação de Sinhô ocorre por meio de um sinsigno indicial remático, que "dirige a atenção para um objeto pelo qual sua presença é determinada" (Peirce, 2012, p. 55).

12 PORTO ALEGRE | v. 19 | n. 32 | 2014 | pp. 08-17 Sessões do Imaginário 


\section{A perspectiva simbólica: \\ Carmen Miranda/Gal Costa}

Gal Costa, em O Mandarim, representa Carmen Miranda (1909-1955), com quem Mário Reis interpretou algumas canções célebres. Antes de sua aparição, ouve-se a gravação de Alô, Alô, de 1934, nas vozes de Mário e Carmen.

Gal, em um primeiro momento, está vestida com uma camisa larga e escura, cabelos soltos (Figura 6). À parte o movimento facial e eventuais sorrisos, sua postura é basicamente fixa. $\mathrm{O}$ fundo se divide horizontalmente: em cima, morros cariocas e nuvens claras; embaixo, água (possivelmente da lagoa Rodrigo de Freitas). O dia é nublado e o resultado é uma fotografia sombria. Ainda não houve indicação de que a cantora representaria algum personagem específico.

Então Gal canta Morena dos Olhos d'Água, de Chico Buarque, em uma interpretação contida, flertando com a bossa nova. Logo em seguida, a fotografia passa a ser em preto e branco. Desta vez Gal canta Camisa Listrada, de Assis Valente, composta em 1933. Carmen Miranda efetivamente gravou esta canção, entre tantas outras de Assis Valente, em 1938. Mas a interpretação de Gal se distancia completamente do ritmo de marchinha que Carmen Miranda e a banda que a acompanhava imprimiam à peça. Aqui, novamente, o compasso é mais lento do que na versão original. Os vibrati no fim dos versos se alongam (diferente dos de Carmen Miranda, que são breves).

Em um terceiro momento, Carmen Miranda é finalmente identificada por Mário Reis. O cantor exclama que ambos "enfeitam a vida". Então, Carmen-Gal 'se despede' com um close que a descreve a partir de baixo, lenço branco balançando ao vento, ao som de Novo Amor, de Ismael Silva. Novamente sua expressão (emoldurada pela cena) é mais "dramática" do que se esperaria.
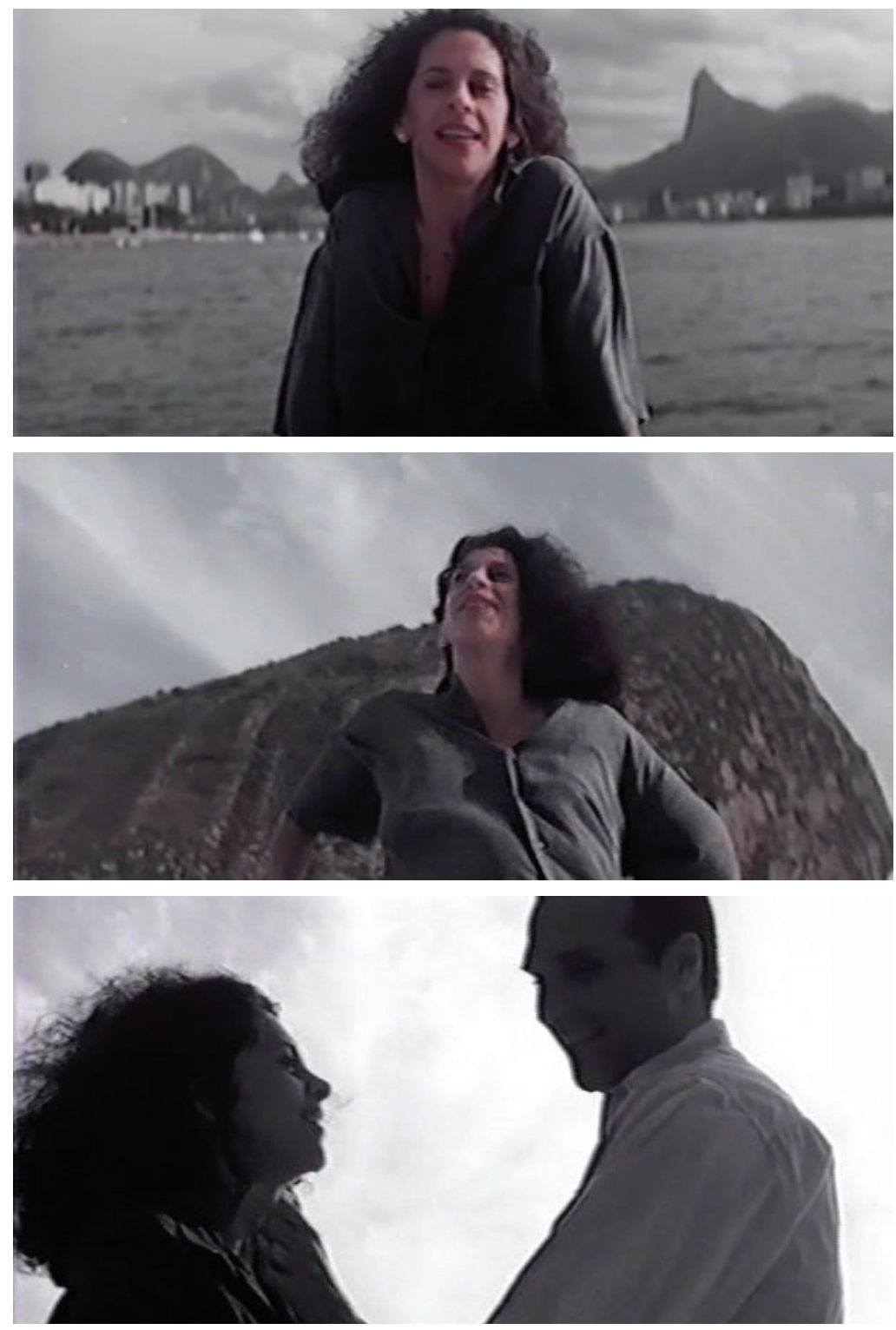

Figuras 6, 7 e 8: Carmen Miranda (interpretada por Gal Costa) canta Chico Buarque, Assis Valente e encontra Mário Reis

Se o diretor estivesse interessado em uma representação mimética, o conceito de Carmen Miranda seria aqui expresso como habitualmente é: revestido de uma "imagem estereotipada de um Brasil sexualmente exposto, hipercolorido e frutal", como disse Caetano (Veloso, 2012, p.263). Mas a significação, aqui, se choca com a designação. Na dimensão da designação, Gal é Carmen Miranda, mas esta dimensão entra em contraste com as estratégias de significação adotadas. O plano de expressão elaborado por Bressane não poderia ser menos solidário ao conceito geralmente significado pela "pequena notável". A colisão se dá em toda parte nestas sequências: a escuridão do ambiente em contraste com a estética tropical e veranil de Carmen Miranda; as roupas discretas em oposição ao traje exótico; a música à capela e mais lenta em oposição ao estilo "alegre e buliçoso" (Severiano, 2008, p.149) de cantar; mesmo a fixidez do gestual de Gal se opõe ao poder expressivo do corpo e dos gestos da designada.

Contudo, surge a marca da designação diegética, neste caso atenuada - há apenas a menção a um apelido de Carmen Miranda: "pequena notável". A conexão entre ambas é realizada por um indicador dentro do próprio contexto do filme. Mas, novamente como na relação Gil-Sinhô, Bressane reconfigura o plano da significação que acompanha o personagem designado. Em Sinhô-Gil, era a intervenção do ator sobre a canção de Sinhô que impunha seu conceito (Gil) ao plano de conteúdo. Agora, são os registros visual (a contenção dos movimentos, a seriedade dos tons escuros) e sonoro (o canto à capela) da expressão de Gal Costa que invertem o conceito habitual de Carmen Miranda, chegando ao ponto de assemelhar-se a um negativo da personagem histórica designada. Ou seja, não se trata mais de 'adicionar' ao conceito, mas de fazer uma representação simbólica por inversão, levando o jogo que envolve designação e significação a um ponto de extrema tensão.

\section{Designações nômades: Tom Jobim}

Em uma cena do trecho final do filme, o músico Edu Lobo participa cantando, diante de Mário/Eiras, Choro 
Bandido, composição sua e de Chico Buarque. Antes, Mário o identifica, de saída: “Tom Jobim!". Então Edu/ Tom diz que trouxe um choro novo pra apresentar a Mário, e que o teria composto com Noel Rosa.

A canção que ele apresenta, contudo, saiu no álbum O Corsário do Rei, de 1985. O disco trazia a trilha, composta por Chico Buarque e Edu Lobo, da peça homônima de Augusto Boal. Da gravação participam vários artistas, entre os quais o próprio Tom Jobim, que, em Choro Bandido, divide o microfone com Edu.

Edu/Tom, voltando ao Mandarim, canta o Choro na íntegra, divergindo pouco de sua interpretação de estúdio (a diferença principal é que aqui temos uma versão acústica, acompanhada somente pelo violão que o próprio Edu toca, enquanto na gravação de 85 ouvem-se piano e cordas). Apesar do suposto ineditismo da canção anunciado por Edu-Tom, no momento em que ele canta "E daí nasceram as baladas/ E os arroubos de bandidos como eu/ Cantando assim/ Você nasceu pra mim/ Você nasceu pra mim", Mário-Eiras abandona a passividade de espectador e intervém, cantarolando um acompanhamento, à maneira de Tom Jobim. As melodias, com esse particular timbre grave e rouco, são recorrentes na obra de Tom?.

Assim, vemos a homenagem que Bressane presta a Tom Jobim, morto no ano anterior ao do lançamento de OMandarim. Fernando Eiras, embora trajado como e designando Mário Reis, aqui faz a vez de Tom, trazendo-o à cena, no plano do conteúdo, por meio do seu modo de cantar. Chega-se à conclusão de que, embora Fernando Eiras, relativamente à dimensão designativa, seja Mário Reis, este Mário Reis, relativamente à dimensão da significação, é Tom Jobim. Edu Lobo, por sua vez, que designava Tom Jobim, apresenta-se no plano de expressão como ele mesmo, Edu, cantando uma composição sua e de Chico. A indicação de Tom Jobim parece, assim, se transpor de Edu Lobo para Fernando Eiras/Mário Reis.
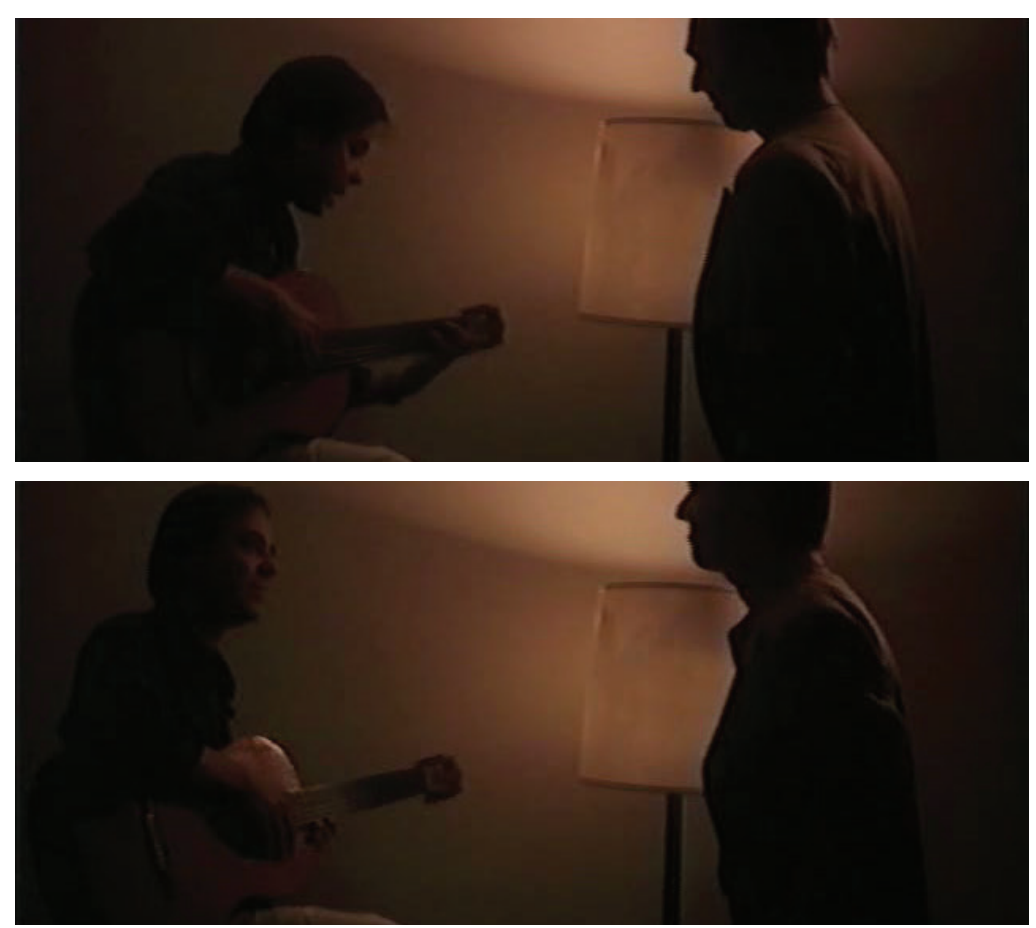

Figuras 9 e 10: Edu Lobo/Tom Jobim e Mário Reis/Fernando Eiras

A designação diegética aparece, nesta sequência, logo no começo ("Tom Jobim!, que prazer em vê-lo"). Mas há também dois momentos em que ocorre uma designação extradiegética: primeiro, quando o modo de cantar de Edu é praticamente idêntico ao da versão presente em $O$ corsário do rei, e vemos a intrusão de seu próprio conceito na representação que faz de Tom Jobim (o procedimento se assemelha ao identificado na relação Sinhô/Gil). Depois, quando é Fernando Eiras (até então designando Mário Reis) que apresenta o trecho de Tom Jobim na canção - e o faz com o estilo habitualmente relacionado ao conceito de Tom (se há uma representação icônica de Tom Jobim na cena, certamente é a de Eiras).
Nesse sentido pode-se dizer que Bressane faz passar aqui um terceiro jogo em que uma designação nômade pode passar, como no caso da indicação de Tom Jobim, de um representâmen a outro. Como diz o poeta: "mesmo que os cantores sejam falsos como eu/ serão bonitas, não importa,/ são bonitas as canções". Designação nômade para um "cinema nômade", como diz Júlio Bressane, "trans-tudo".

\section{Designações múltiplas ou politonais}

O cantor e compositor Chico Buarque de Hollanda (1944) interpreta, em O Mandarim, o cantor e compositor Noel Rosa (1910-1937), sendo assim identificado desde o começo ("Eu sou Noel Rosa", "de Vila Isabel").

Chico executa (Figuras 11 e 12), com voz e violão, Provei e Filosofia, ambas de Noel Rosa (1936 e 1933, respectivamente), diante de Mário Reis e de duas moças. São claras suas idiossincrasias performáticas costumeiras: o timbre vocal, o sotaque (outra possibilidade seria imitar o modo de pronunciar o $\mathrm{R}$ da época de Noel), uma estreita relação com o ritmo e a harmonia produzidos no violão 'bossanovista', etc. Mas o resultado é singular porque o estilo de Chico, em muitos aspectos, é uma continuidade do de Noel. Representá-lo no filme não significou, para Chico, um esforço de interpretação como o de Eiras relativamente a Mário Reis. Sua atuação habitual, em certo sentido, é a de Noel Rosa: sabe-se que Chico já foi considerado um promotor do velho samba (Severiano, 2008, p. 364) e comparado a Noel pela delicadeza das letras. Além disso, Filosofia já faz parte de sua obra: foi interpretada no álbum Chico Canta, de 1973. Bressane parece indicar uma certa indissociabilidade entre Chico e Noel, o que é reforçado na sequência em que Edu Lobo representa Tom Jobim,

14 PORTO ALEGRE | v. 19 | n. 32 | 2014 | pp. 08-17 Sessões do Imaginário 
anunciando que escreveu uma canção com Noel Rosa. Choro Bandido, que ele então apresenta, é, na verdade, uma composição sua (Edu) e de Chico.
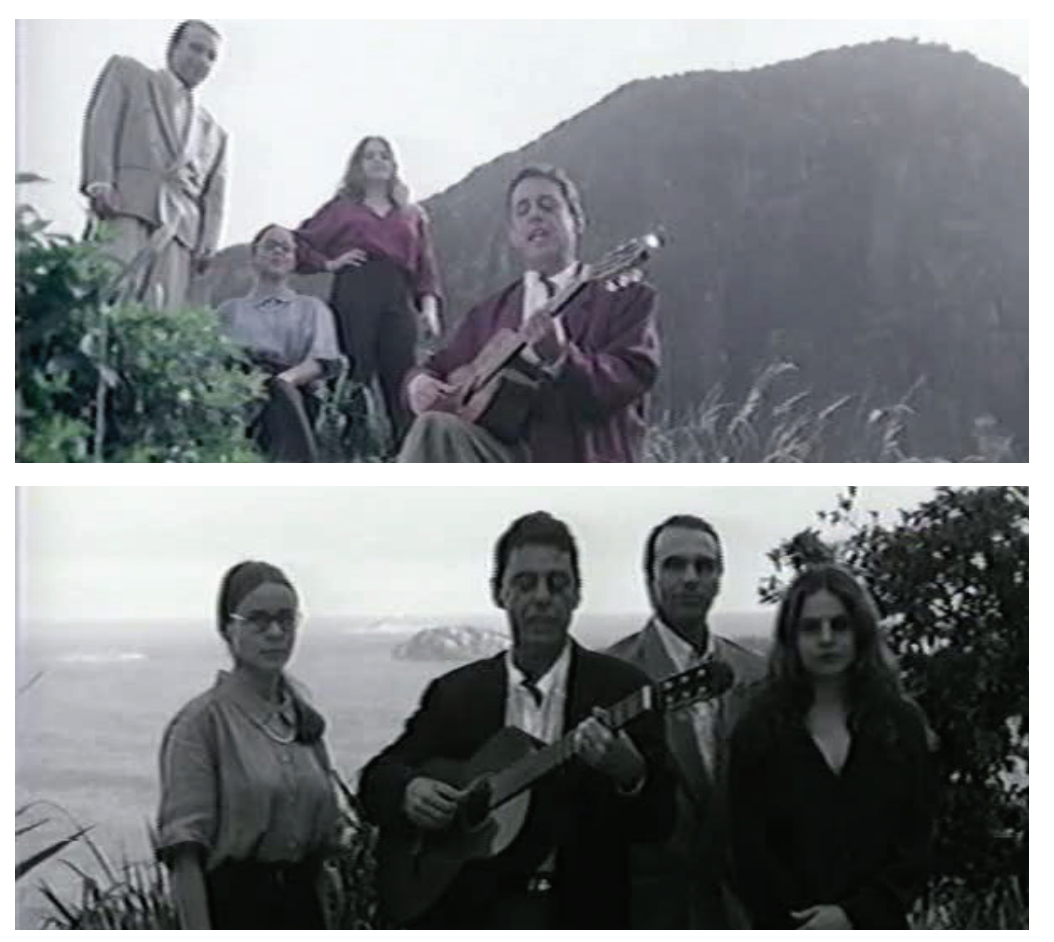

Figuras 11 e 12

Voltemos, contudo, à primeira aparição do personagem Noel em O Mandarim, que entra em cena caminhando em direção à câmera, numa paisagem tropical. Acompanha-o, na trilha sonora, a canção $A$ Banda. Como se sabe, esta foi composta por Chico Buarque em 1966. Sabe-se menos, porém, que Mário Reis gravou uma versão própria em seu derradeiro disco, de 1971. E esta é a versão utilizada por Bressane para introduzir Noel. De modo que, agora, é Chico quem é interpretado por uma de suas maiores influências (Mário), ao mesmo tempo em que Chico interpreta Noel. O papel designativo de Chico em O Mandarim passa, assim, a se estender também a Mário: tudo indica que o foco passa de uma de- signação identitária para uma designação múltipla: Mário interpreta Chico, que é intérprete de Noel, que tem como um de seus maiores intérpretes Mário Reis, que é grande influência de Chico.

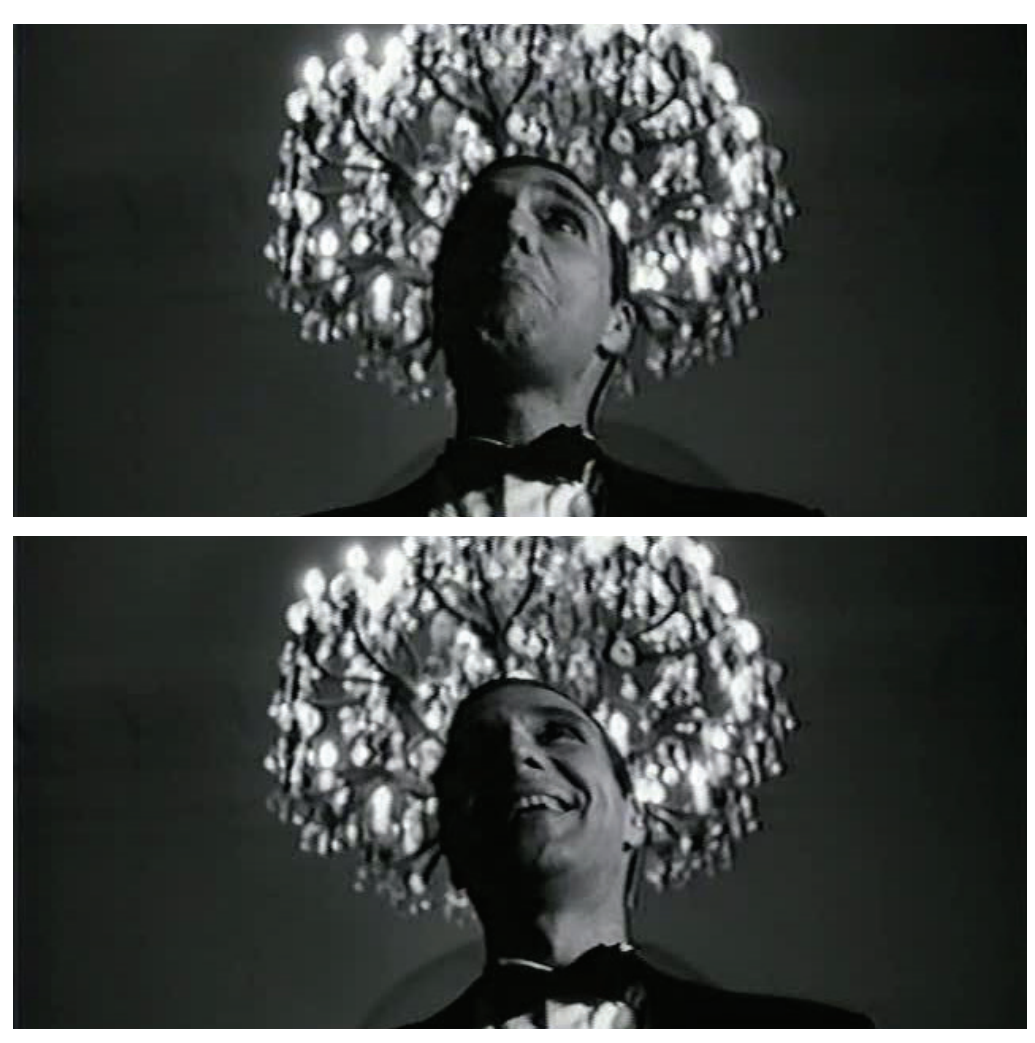

Figuras 13 e 14

Em outra cena, o personagem Mário (Figuras 13 e 14), interpretado por Fernando Eiras, canta Voltei a Cantar, de Noel Rosa, com a câmera centralizada em seu rosto. Na trilha sonora, concomitantemente, ouve-se Na esquina da vida, também de Noel. A sobreposição, um tanto perturbadora, articula uma prática politonal: a justaposição de dois ou mais campos tonais (Ross, 2011, p.97), ou seja, duas tonalidades que mantêm, cada uma, sua organização interna intocada (em acordo com o paradigma diatônico ocidental), mas que são sobre- postas para causar um dos efeitos mais relevantes para a "libertação da dissonância" que a música do século XX operou (Ross, 2011, p.98). O importante, aqui, é notar que Bressane configura esta politonalidade tanto em termos musicais (via união das canções) quanto em termos de designação. Não se pode atribuir ao representâmen Fernando Eiras uma identidade pura: há múltiplos referentes sobrepostos, quase como numa 'dissonância designativa'.

Esta configuração aponta para um terceiro jogo de designação engendrado por Bressane, em que um ator já não se atém a uma identidade, já que pode passar, a um só tempo, por várias identidades incompossíveis; já que pode designar, a um só tempo, seu personagem, toda uma corrente histórica de sambistas e a si mesmo. Designação politonal, "transbordante", processo de singularização não-identitário.

\section{Considerações}

Júlio Bressane e os jogos de designação buscou identificar, na esteira das provocações de Jacques Aumont em As Teorias dos Cineastas (2004), elementos de uma teoria latente na obra do diretor marginal carioca. Pode-se reconhecer, a partir de uma série de sequências do filme $O$ Mandarim, observadas do ponto de vista das dimensões da proposição, que Bressane desconstroi a designação enquanto relacionada com uma forma de verdade. De um lado, explodida numa proliferação múltipla de identidades (Chico, que designa toda a história do samba desde Noel), e, de outro, autonomizada e circulando livremente (Tom Jobim, que é indicado por mais de um representâmen), a lógica designativa dá lugar, no cinema de Bressane, a uma função de fabulação.

15 PORTO ALEGRE | v. 19 | n. 32 | 2014 | pp. 08-17 Sessões do Imaginário 
A fabulação aparece quando o cinema já não é mais representativo de objetos pré-existentes, e quando o movimento não se restringe ao sistema sensório-motor (em que o movimento recebido se prolonga numa nova ação determinada). Mas também quando as narrações são falsificantes: o tempo não é mais cronológico, já que pode passar por presentes incompatíveis ou passados não-necessariamente verdadeiros. É crônico, e apresentado diretamente, já que a tendência dos movimentos não é mais a resolução lógica e econômica das tensões, mas justamente o movimento anormal, essencialmente falso, de realidades superpostas.

É por meio dessa injeção de tempo crônico na forma de verdade que o cineasta se torna propriamente artista, 'flagrado em delito de criação de mitos e lendas', libertando a potência do falso (Deleuze, 1986, p. 155-188). A lógica de designação, em Bressane, se deixa contaminar por uma tal potência de falseamento, guardando compromisso não com a identificação, mas somente com a expansão do sentido, quarta dimensão da proposição.

Paralelamente a uma tese desconstrucionista e fabuladora, Bressane afirma uma proposição sobre a natureza pré-individual da criação compartilhada com Deleuze, que afirma (considerando a literatura): "desde que se atribui um livro a um sujeito, negligencia-se este trabalho das matérias e a exterioridade de suas correlações. Fabrica-se um bom Deus para movimentos geológicos" (Deleuze, 1995, p. 10).

Contra os deuses, os sujeitos, os autores, Bressane - ironicamente uma das máximas expressões do cinema de autor no Brasil - em OMandarim leva a lógica da designação ao paroxismo para demonstrar, com grande rigor e sensibilidade, a anterioridade ontológica da fabulação, que faze desfaz até o limite da indecidibilidade as designações que a um tempo nos tranquilizam e nos enclausuram.
Referências

AUMONT, Jacques. As teorias dos cineastas. Campinas: Papirus, 2004

AUMONT, Jacques; MARIE, Michel. Dicionário teórico e crítico de cinema. Campinas: Papurus, 2006.

BRESSANE, Júlio. Alguns. Rio de Janeiro: Imago, 1996.

Cinemancia. Rio de Janeiro: Imago, 2000.

Fotodrama. Rio de Janeiro: Imago, 2005.

DELEUZE, Gilles. Lógica do sentido. São Paulo: Perspectiva, 1975.

se, 1986.

A imagem-tempo São Paulo: Brasilien-

DELEUZE, Gilles ; GUATTARI, Félix. Mil platôs v. 2. Rio de Janeiro: editora, 34, 1995.

PEIRCE, Charles S. Semiótica. São Paulo: Perspectiva, 2012.

SILVA, Alexandre Rocha da; ARAUJO, André Corrêa da Silva de; MELLO, Jamer Guterres de; CONTER, Marcelo Bergamin. Deleuze e a Semiótica Crítica. Semeiosis. [suporte eletrônico] Disponível em: <http://www.semeiosis.com.br/u/61>. Acesso em: 24 jul. 2014.

ROSS, Alex. O resto é ruído: escutando o século $X X$ São Paulo: Companhia das Letras, 2011.

SEVERIANO, Jairo. Uma história da música popular brasileira. São Paulo: Editora 34, 2008.
VELOSO, Caetano. Verdade tropical. São Paulo: Companhia das Letras, 2012.

\section{Referências audiovisuais}

BRESSANE, Júlio. 0 mandarim. [Filme-vídeo]. Roteiro e direção de Júlio Bressane. Direção de produção de Raquel Couto. Líder, Rio de Janeiro, Brasil, 1995. 90 min. color. son.

. Barão Olavo, o Horrível. [Filme-vídeo]. Direção de Júlio Bressane. Brasil. 1970. 72 min. color. son.

. Brás Cubas. [Filme-vídeo]. Direção de Júlio Bressane. Brasil, 1985. $92 \mathrm{~min}$. color. son.

. Cinema inocente. [Filme-vídeo]. Direção de Júlio Bressane. Brasil, 1979. 39 min. color. son.

Tabu. [Filme-vídeo]. Direção de Júlio Bressane. Brasil, 1982. 79 min. Black

and White. pb.son.

BRESSANE, Júlio; ESCOREL, Eduardo. Bethânia bem de perto - A propósito de um show. [Filme-vídeo]. Direção de Eduardo Escorel e Júlio Bressane. Brasil, 1966. 33 min. pb. son.

BUARQUE DE HOLLANDA, Chico. A banda. Chico Buarque de Hollanda. Intérprete: Chico Buarque. Brasil. RGE, 1966. LP. 
Morena dos olhos d'água. Chico Buarque de Hollanda - Volume 2. Intérprete: Chico Buarque. Brasil. RGE, 1967. LP.

FILHO, André. Alô, Alô. Intérpretes: Mário Reis e Carmen Miranda. 1934.

LAMARTINE, Babo. Voltei a cantar. Intérprete: Mário Reis. 1971 - Odeon - MOFB 3690 -

LOBO, Edu; BUARQUE DE HOLLANDA, Chico. Choro bandido. Paratodos. Brasil. 1993. CD.

ROSA, Noel; FILHO, André. Filosofia. NR012. Intérprete: Mário Reis, 1933.

ROSA, Noel; VADICO. Provei. NR027. (Noel Rosa e Vadico). Marília Batista e Noel Rosa, 1936.

SILVA, Ismael. Novo amor. Gravação. 1929.

SINHÔ. Jura. Gravação. 1938.

VALENTE, Assis. Camisa listrada. Intérprete. Marlene. Choro. 1937.

Gosto que me enrosco. Gravação. Intérprete: Mário Reis. 1928.

Sabiá. Gravação. Intérprete: Mário Reis. 1928. Sessões do Imaginário

\footnotetext{
17 PORTO ALEGRE | v. 19 | n. 32 | 2014 | pp. 08-17
}

Notas

1 Doutor em Ciências da Comunicação pela Universidade do Vale do Rio dos Sinos (2003), com pós-doutorado na Universite de Paris III (Sorbonne-Nouvelle). Pesquisador do CNPq (bolsista produtividade) e professor do Programa de Pós-Graduação em Comunicação e Informação da Faculdade de Biblioteconomia e Comunicação da Universidade Federal do Rio Grande do Sul (PPGCOM/UFRGS - Rua Ramiro Barcelos, 2705, $2^{\circ}$ andar, Santana, CEP: 90035-007, Porto Alegre/RS - Brasil). E-mail: arsrocha@gmail.com.

2 Graduando em Jornalismo na Faculdade de Biblioteconomia e Comunicação da UFRGS. Bolsista FAPERG. Integra o Diretório CNPq Semiótica e Culturas da Comunicação (GPESC). (FABICO/UFRGS - Rua Ramiro Barcelos, 2705, Santana, CEP: 90035-007, Porto Alegre/RS - Brasil).E-mail: cassioborba@gmail.com.

3 Os filmes da Belair, todos de 1970, são: Barão Olavo, o horrivel; Cuidado, madame; A familia do barulho (dirigidos por Bressane) e Carnaval na lama; Copacabana, mon amour; Sem essa aranha; A miss e o dinossauro (dirigidos por Sganzerla).

4 Conceitos de Louis Hjelmslev, revisitados por Deleuze e Félix Guattari em Mil Platôs (Deleuze, Guattari, 1995, pp. 11-50). Para Hjelmslev, a função semiótica éa solidariedade que liga conteúdo e expressão. A expressão terá sua forma, que, no caso da pronúncia de uma palavra, se impõe sobre a substância que é a cadeia fonética. O conteúdo a que a expressão se conecta, semelhantemente, passará por um movimento de modelagem exercido pela forma em relação à sua substância do conteúdo. (Hjelmslev, 1975, p.54-64)
5 Sabe-se que o ícone não se reduz à ideia de semelhança (há índices que se expressam como imagens, como diagramas, como metáforas), mas aqui é este o traço relevante para que se possam pensar as estratégias de Bressane para a desconstrução da designação.

6 "Talvez o mais importante de um poeta seja sua voz. As ideias? Que importam as ideias? A voz! Humano instrumento da emoção"

7 Pode-se ouvi-lo assim cantarolando, por exemplo, em Águas deMarço (não na primeira versão, do Matita Perê de 1973, mas na gravação com Elis Regina de 1974) e mais notavelmente ainda em Pra Dizer Adeus (do álbum Edu \& Tom, de 1981).

8 A noção leibniziana de compossibilidade pretendia sanar o paradoxo dos futuros contingentes: como evitar que seja absurdo dizer que uma batalha naval pode ocorrer amanhã (já que, se ela ocorre, é falso que ela tenha podido não ocorrer e que, se ela não ocorre, é falso que ela tenha em qualquer momento podido)? As hipóteses, contudo, não seriam impossíveis, mas incompossíveis, não podendo ocorrer num mesmo mundo (Deleuze, G. 1986, p. 160). 